\title{
GENETIC VARIATION IN DIPLOID DACTYLIS \\ II. EMERGENCE DATE AND SOME MORPHOLOGICAL AND PHYSIOLOGICAL LEAF CHARACTERS
}

\author{
P. F. PARKER
}

Hartley Botanical Laboratories, The University, Liverpool, 3

Received 10.xi.67

\section{INTRODUCTION}

THIS paper is a continuation of an investigation into the genetic variation present in subspecies of diploid Dactylis, the first part of which has been published (Parker, 1968). In the following account, the methods of analysis developed by Jinks (1954), Hayman $(1954,1958)$ and Dickinson and Jinks (1956) are again used.

\section{Materials AND Methods}

The $9 \times 9$ diallel cross described previously (Parker, 1968) was transplanted to the field in late March 1964 in an identical layout to the seedling experiment ( 3 blocks, 12 plants per replicate). The same subspecies numbers as before are used in the graphs (see fig. 1), and the characters considered are:

(i) Emergence date, taken as the number of days after lst April.

(ii) Area of flag leaf on the first panicle. Computed as length $\times$ breadth $\times$ Kemps (1960) correction factor.

(iii) Summer leaf area. Computed as (ii).

(iv) Leaf dry weight. Estimated from one gram bulk samples of leaf tissue in each replicate.

(v) Total chlorophyll content. Computed as mg./gram fresh weight and dry weight.

In the last three characters mentioned, sampling technique had to be considered carefully. For summer leaf area, a well-developed tiller on each plant was selected, and the second mature leaf below the top was measured, this means that the leaves are not homotypes as in the case of leaf six and the flag leaf.

With total chlorophyll content, the considerable time and labour involved in preparing homogenates for spectrophotometric analysis meant that only a sub-sample of leaf tissue was taken from a bulk sample of two recently matured leaves collected from each plant in the replicate. As soon as possible after collection, the centre sections of the leaves of the bulk samples were removed, a sub-sample of at least one gram taken for dry weight estimation, and a separate sub-sample of half to one gram taken for analysis, depending upon the size of the individual leaves. This second sub-sample was macerated in 80 per cent. acetone and anhydrous sodium carbonate, and the chlorophyll extract prepared according to the method of Arnon (1949). The spectrophotometric determination of chlorophyll was made on 
a Unicam S.P. 500 spectrophotometer, using the equations given by Arnon (loc. cit.) for 80 per cent. acetone extracts, with optical density measurements at $663 \mathrm{~m} \mu, 645 \mathrm{~m} \mu$ and $652 \mathrm{~m} \mu$, using the specific absorption coefficients given by Mackinnay (1941).

The analysis of leaf dry weight was carried out on the samples dried for use in chlorophyll estimations. These samples are small, and can only be considered as an estimate of the dry weight of the leaves, not the whole plant.

The environmental component of variation $\left(E_{2}\right)$, was derived from the between blocks total interaction mean square from the analysis of variance, and appropriately calculated for $V r$ and $W r$ (Jinks, 1954), but in only two analyses (leaf dry weight, and chlorophyll $\mathrm{mg}$./gm. dry weight) was it large enough to significantly alter the level of dominance expressed in the graphs. In these two cases the corrected ordinate and abcissa have been put in as broken lines on the $W r / V r$ graphs.

As in the previous paper (Parker, 1968) Wearden's (1964) test of the (a) M.S. against the $(c)$ M.S. and the $(b)$ M.S. against the $(d)$ M.S. was included whenever $(c)$ and $(d)$ were significant. The conclusion from this test overriding that from tests made agaisnt block interactions if the two disagree about the significance of $(a)$ and $(b)$.

\section{Results}

\section{(i) Emergence date}

The mean emergence date, calculated as the number of days after lst April, are presented in table 1, and the corresponding Hayman's analysis in table 2. In the analysis of variance, all items were tested against their

TABLE 1

Mean data for emergence date as number of days after 1st April

\begin{tabular}{|c|c|c|c|c|c|c|c|c|c|}
\hline 우 & $\begin{array}{l}0 \\
1\end{array}$ & 2 & 3 & 4 & 5 & 6 & 7 & 8 & 9 \\
\hline 1. & $40 \cdot 2$ & $27 \cdot 7$ & 37.3 & $37 \cdot 4$ & $35 \cdot 0$ & $40 \cdot 9$ & $35 \cdot 7$ & $29 \cdot 0$ & $30 \cdot 1$ \\
\hline 2. & $29 \cdot 8$ & $42 \cdot 8$ & $42 \cdot 5$ & 42.5 & $44 \cdot 0$ & $47 \cdot 4$ & $36 \cdot 3$ & $32 \cdot 0$ & 37.2 \\
\hline 3. & $34 \cdot 2$ & $42 \cdot 9$ & 44.0 & 40.5 & $45 \cdot 0$ & $44 \cdot 2$ & $38 \cdot 5$ & 38.9 & $37 \cdot 7$ \\
\hline 4. & $36 \cdot 5$ & $43 \cdot 7$ & $44 \cdot 4$ & $49 \cdot 4$ & $42 \cdot 8$ & $45 \cdot 9$ & $40 \cdot 5$ & 34.9 & 39.9 \\
\hline 5. & $36 \cdot 5$ & $45 \cdot 4$ & $40 \cdot 8$ & $46 \cdot 3$ & $51 \cdot 3$ & $49 \cdot 9$ & $40 \cdot 5$ & $35 \cdot 2$ & $44 \cdot 2$ \\
\hline 6. & $40 \cdot 7$ & $47 \cdot 4$ & $44 \cdot 8$ & $48 \cdot 6$ & $46 \cdot 4$ & $55 \cdot 4$ & $41 \cdot 3$ & 38.7 & $43 \cdot 1$ \\
\hline 7. & 31.7 & $35 \cdot 2$ & $37 \cdot 8$ & $39 \cdot 1$ & $39 \cdot 7$ & $42 \cdot 7$ & $40 \cdot 0$ & $33 \cdot 4$ & $39 \cdot 8$ \\
\hline 8. & 28.9 & 33.4 & $34 \cdot 9$ & $40 \cdot 1$ & $34 \cdot 7$ & $37 \cdot 5$ & $35 \cdot 8$ & 31.7 & 33.0 \\
\hline 9. & $33 \cdot 6$ & $37 \cdot 0$ & $38 \cdot 8$ & $41 \cdot 1$ & $42 \cdot 4$ & $44 \cdot 0$ & 37.7 & $33 \cdot 6$ & $39 \cdot 1$ \\
\hline
\end{tabular}

own error variances, as Bartlett's test of homogeneity was of borderline significance $\left(\chi^{2}{ }_{(5)}=11.5 ; \quad P=0.05-0.02\right)$. The significance of item (a) indicates the presence of genetic variation between the parental populations. The significance of item $(b)$ indicates the presence of dominance variation, 
all the components of $(b)$ are significant, item $\left(b_{1}\right)$ being the largest, points to the presence of heterosis, item $\left(b_{2}\right)$ indicates gene asymmetry, and item $\left(b_{3}\right)$ inconsistent (specific) dominance interactions. The $(c)$ and $(d)$ items representing consistent and inconsistent reciprocal differences, are both significant. Wearden's (1964) test, however, shows that $(c)$ is not significantly larger than the $(d)$ item, and neither of these appear to contribute a great deal to the genetic variation present.

TABle 2

Hayman's analysis of variance of emergence date. Wearden's test is included as both (c) and (d) are significant

\begin{tabular}{|c|c|c|c|c|c|}
\hline Item & D.F. & M.S. & V.R. & \multicolumn{2}{|c|}{ Wearden's Test } \\
\hline$a$ & 8 & $734 \cdot 81$ & $96 \cdot 64 * * *$ & $\frac{a}{c}$ & $130 \cdot 05 * * *$ \\
\hline$b_{1}$ & 1 & $548 \cdot 85$ & $819 \cdot 64 * * *$ & $\frac{b_{1}}{d}$ & $73.97 * * *$ \\
\hline$b_{2}$ & 8 & 23.09 & $15 \cdot 52 * * *$ & $\frac{b_{2}}{d}$ & $3 \cdot 11 *$ \\
\hline$b_{3}$ & 27 & 18.95 & $7 \cdot 20 * * *$ & $\frac{b_{3}}{d}$ & $2 \cdot 55^{* *}$ \\
\hline$b$ & 36 & 34.59 & $14 \cdot 89 * * *$ & $\frac{b}{d}$ & $4 \cdot 66^{* * *}$ \\
\hline$c$ & 8 & $5 \cdot 65$ & $4 \cdot 88 * *$ & $\frac{c}{d}$ & -N.S. \\
\hline$d$ & 28 & $7 \cdot 42$ & $2 \cdot 26 * *$ & & 一 \\
\hline Total & 80 & - & - & & 一 \\
\hline$B$ & 2 & $8 \cdot 18$ & - & & - \\
\hline$B a$ & 16 & $7 \cdot 60$ & - & & 一 \\
\hline$B b_{1}$ & 2 & $0 \cdot 67$ & 一 & & - \\
\hline$B b_{2}$ & 16 & 1.49 & - & & 一 \\
\hline $\mathrm{Bb}_{3}$ & 54 & $2 \cdot 63$ & 一 & & - \\
\hline$B b$ & 72 & $2 \cdot 32$ & 一 & & - \\
\hline$B c$ & 16 & $1 \cdot 16$ & 一 & & - \\
\hline$B d$ & 56 & $3 \cdot 28$ & - & & - \\
\hline Total & 242 & - & - & & - \\
\hline
\end{tabular}

Analysis of the data may be extended by the methods of Jinks (1954) and Hayman (1954), which were further developed by Dickinson and Jinks (1956) to include a diallel cross between heterozygous parents. These methods use the array variances $(V r)$ and covariances $(W r)$ within arrays of family means with the non-recurrent parent.

As all progenies were derived from the bulked seed of five pair crosses, maternal effects were assumed to be independent of genotype, and the values of $W r$ and $V r$ calculated from family means averaged over reciprocals as well as blocks. The regression of $W r$ on $V r$ is highly significant $(b=0.747 \pm 0.102 ; \mathbf{P}=0.001)$ (fig. 1). This line cuts the $W r$ axis above the origin, indicating incomplete dominance which is directional for earliness, as the correlation of parental emergence dates upon $(W r+V r)$ is significant 


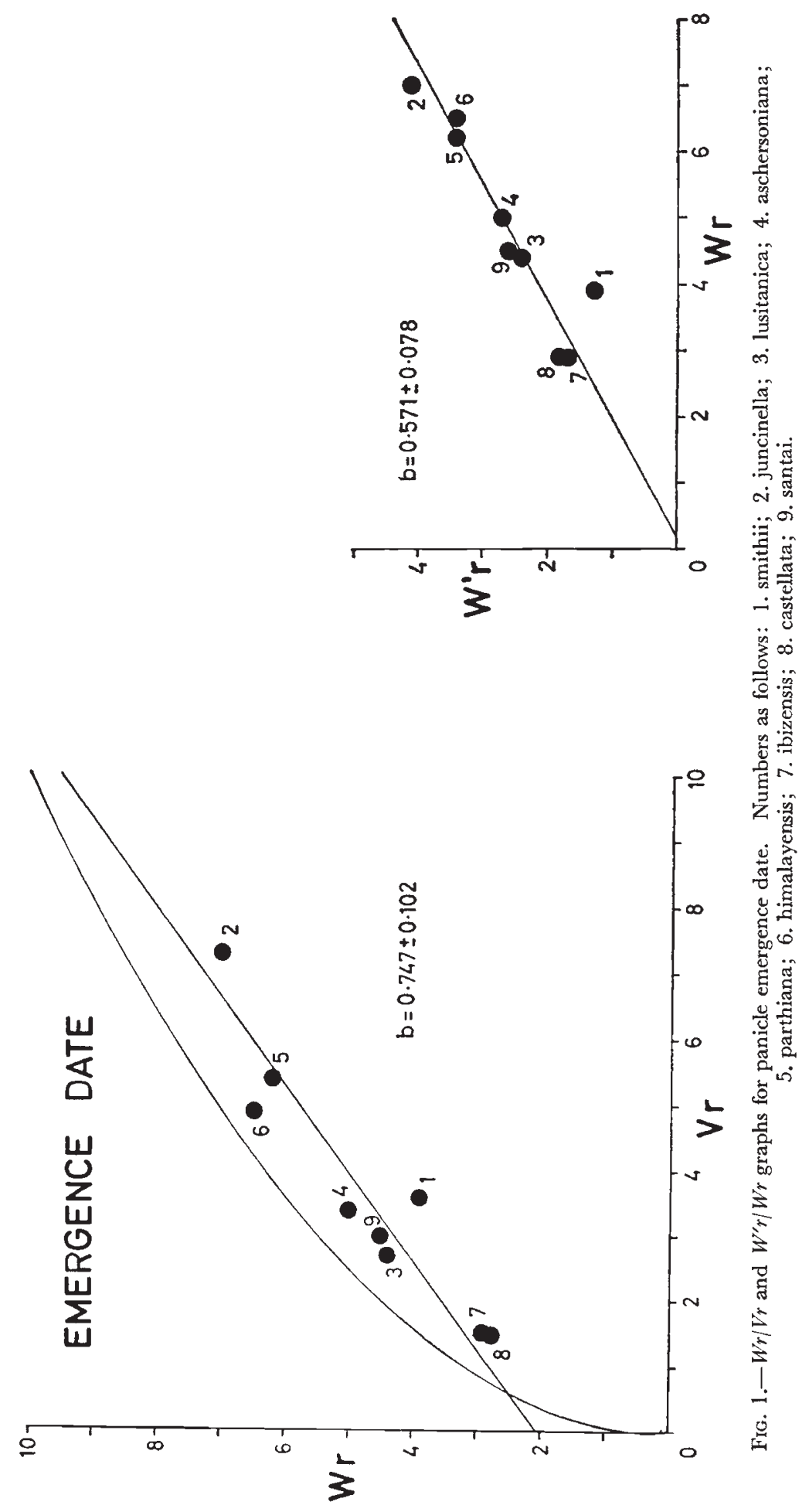


$\left(r=0.651^{*}\right)$. The regression of $W^{\prime} r$ (covariance of progeny mean on to non-recurrent array mean) upon $W r$ (Hayman, 1958), is also significant $(0.571 \pm 0.078 ; \quad P=0.001)$ and gives a similar distribution of parental array points.

\section{(ii) Flag leaf area}

The mean area data are presented in table 3 and the results of Hayman's analysis in table 4. Bartlett's test shows the six error variances to be homogenous $\left(\chi^{2}{ }_{(5)}=4 \cdot 0 ; P=0 \cdot 7\right)$, all components of the analysis are therefore tested against the common error item $(B t)$.

TABLE 3

Mean data for flag leaf area in $\mathrm{mm} .^{2}$

\begin{tabular}{|c|c|c|c|c|c|c|c|c|c|}
\hline & t & & & & & & & & \\
\hline 우 & 1 & 2 & 3 & 4 & 5 & 6 & 7 & 8 & 9 \\
\hline 1. & 399.8 & $536 \cdot 4$ & $972 \cdot 8$ & 937.2 & $799 \cdot 7$ & $562 \cdot 8$ & $597 \cdot 1$ & 491.5 & $732 \cdot 2$ \\
\hline 2. & $378 \cdot 7$ & $159 \cdot 2$ & $448 \cdot 3$ & $460 \cdot 9$ & $456 \cdot 6$ & $370 \cdot 0$ & $442 \cdot 0$ & 388.6 & $444 \cdot 3$ \\
\hline 3. & $780 \cdot 7$ & $499 \cdot 0$ & 853.0 & $1188 \cdot 3$ & $924 \cdot 1$ & $846 \cdot 1$ & $719 \cdot 7$ & 1093.7 & $1046 \cdot 2$ \\
\hline 4. & 738.9 & 511.6 & $561 \cdot 7$ & 804.9 & $872 \cdot 2$ & 912.2 & $873 \cdot 3$ & 994.9 & $927 \cdot 0$ \\
\hline 5. & $651 \cdot 1$ & $395 \cdot 3$ & 1233.5 & $821 \cdot 1$ & $791 \cdot 0$ & $1051 \cdot 4$ & $687 \cdot 7$ & $906 \cdot 1$ & $754 \cdot 0$ \\
\hline 6. & $795 \cdot 4$ & 436.9 & $775 \cdot 0$ & $860 \cdot 2$ & $1016 \cdot 3$ & $1074 \cdot 3$ & $809 \cdot 2$ & $912 \cdot 1$ & $889 \cdot 6$ \\
\hline 7. & $549 \cdot 0$ & $402 \cdot 3$ & $687 \cdot 7$ & $855 \cdot 4$ & $670 \cdot 4$ & 683.6 & 465.8 & $581 \cdot 4$ & 463.2 \\
\hline 8. & 744.5 & $595 \cdot 9$ & $925 \cdot 4$ & 929.9 & $816 \cdot 8$ & $820 \cdot 9$ & $555 \cdot 4$ & 679.9 & $810 \cdot 0$ \\
\hline 9 & 844.9 & $480 \cdot 1$ & $860 \cdot 1$ & $904 \cdot 6$ & $787 \cdot 3$ & $794 \cdot 1$ & $667 \cdot 3$ & $1097 \cdot 4$ & $579 \cdot 6$ \\
\hline
\end{tabular}

There is significant genetic variation between the parental populations (item a), also a significant main dominance component (item $b$ ). The components of dominance are all significant, the largest being $\left(b_{1}\right)$ indicating considerable heterosis in crosses between populations. There appears to be some gene asymmetry $\left(b_{2}\right)$ and specific inconsistent reciprocal effects $\left(b_{3}\right)$ present. Both items $(c)$ and $(d)$ are significant, indicating the presence of both consistent and inconsistent reciprocal differences.

Wearden's (1964) test shows that only the $(a)$ component is significant, suggesting that genetic variation is mainly additive, with a background of nuclear/cytoplasmic interactions.

The $W r / V r$ analysis (fig. 2) shows a regression line not significantly different from one $(b=0.998 \pm 0.195 ; P=0.01)$. This cuts the $W r$ axis positively, indicating incomplete dominance; this is ambidirectional, there being no correlation between $\mathrm{P}$ and $(W r+V r)$. The $W^{\prime} r / W r$ graph (fig. 2) also gives a significant regression $(b=0.360 \pm 0.045 ; \quad P=0.001)$. This cuts the $W^{\prime} r$ axis positively and is significantly different from +0.50 $\left(t_{(7)}=0.02-0.01\right)$. The order of parental points, however, is similar to those of the $W r / V r$ graph. 
TABLE 4

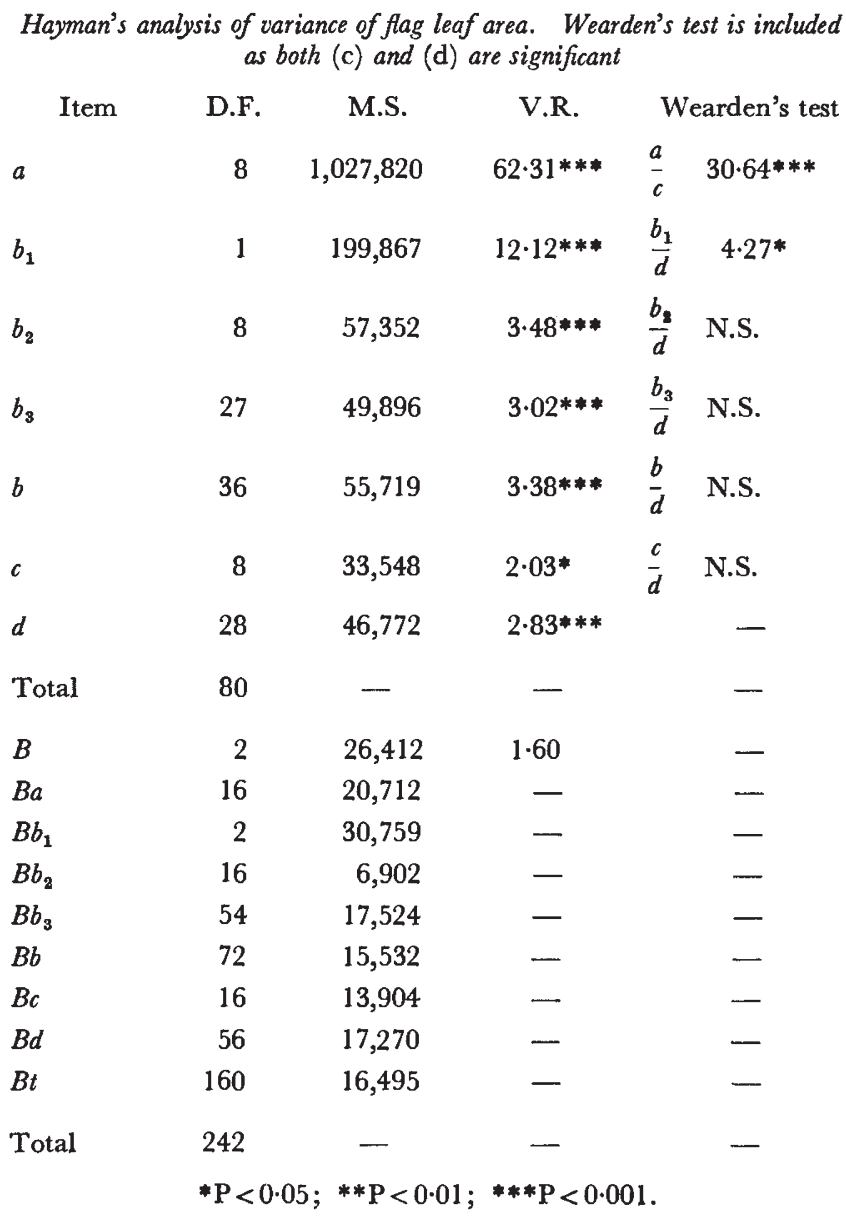

(iii) Summer leaf area

The area was computed as for flag leaf, the mean data are presented in table 5 and Hayman's analysis in table 6.

Application of Bartlett's test showed that the error variances were homogeneous $\left(\chi_{(5)}^{2}=3 \cdot 2 ; \mathrm{P}=0 \cdot 7\right)$ therefore all components were tested against the common error variance $(B t)$. The analysis of variance showed significant genetic variation between the parental populations (item a), the main component of dominance (item $b$ ) is also significant. The significance of the components of $(b)$ suggest the presence of gene asymmetry $\left(b_{2}\right)$, and specific inconsistent dominance relationships $\left(b_{3}\right)$. The significance of item $(c)$ indicates the presence of consistent reciprocal differences; $(c)$ is, however, not significantly greater than $(d)$. Finally, there is some evidence that either the difference in environment, or variation in sampling technique, the leaves not being homotypes, has caused some difference in leaf areas between blocks (item $B$ ).

The graphical $\mathrm{Wr} / \mathrm{Vr}$ analysis (fig. 3) shows a significant regression line 


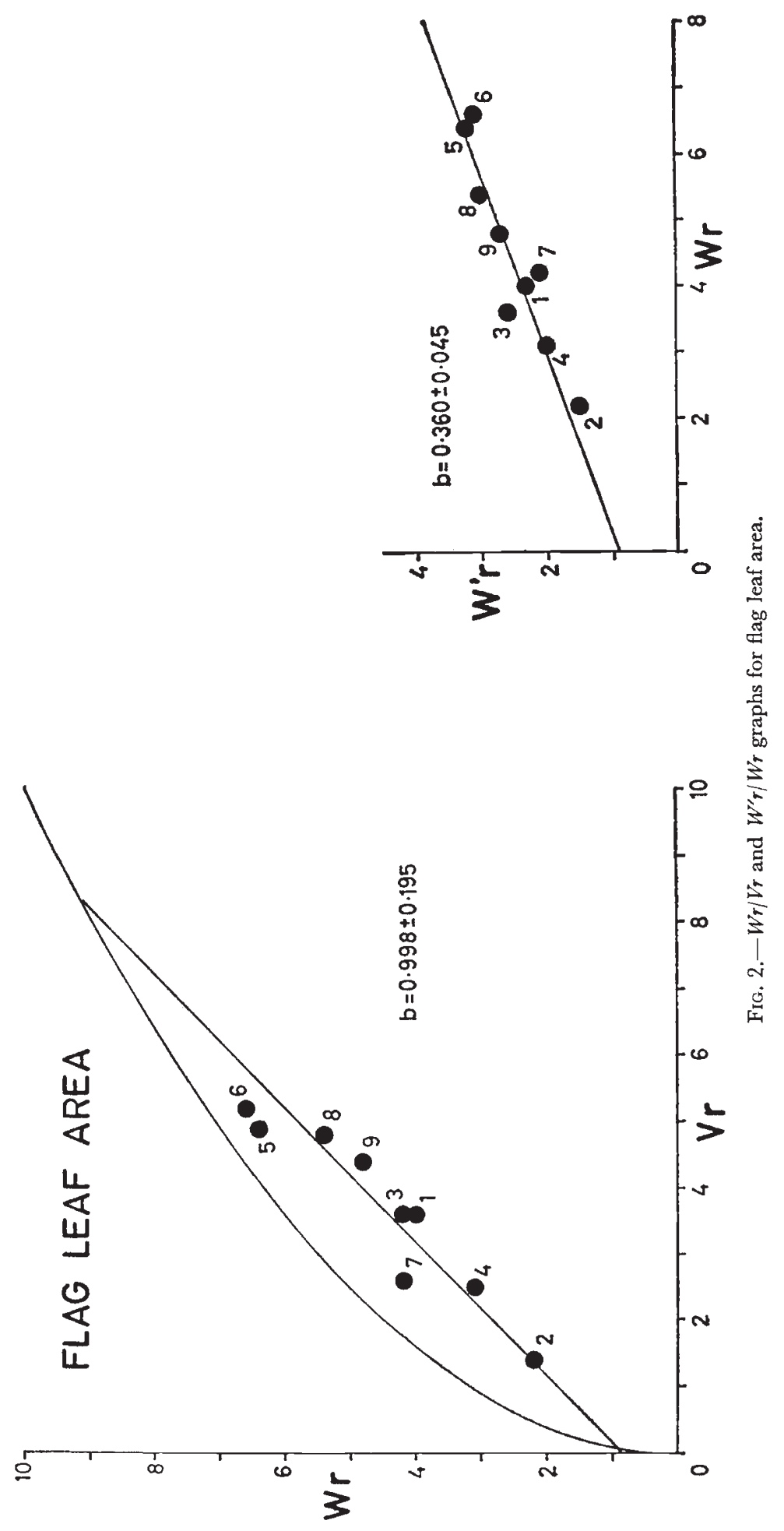


TABLE 5

Mean data for summer leaf area in $m$. $^{2}$

\begin{tabular}{|c|c|c|c|c|c|c|c|c|c|}
\hline & $\sigma^{\pi}$ & & & & & & & & \\
\hline 2 & 1 & 2 & 3 & 4 & 5 & 6 & 7 & 8 & 9 \\
\hline 1 & $340 \cdot 73$ & $585 \cdot 23$ & 621.91 & $642 \cdot 35$ & $694 \cdot 72$ & 870.89 & $306 \cdot 66$ & 372.08 & 458.06 \\
\hline & $54 \cdot 72$ & 903.68 & $468 \cdot 66$ & 1445.53 & $1181 \cdot 34$ & $1520 \cdot 13$ & $757 \cdot 66$ & $979 \cdot 42$ & $1296 \cdot 79$ \\
\hline & 855.06 & 737.51 & 1730.99 & $1547 \cdot 18$ & 1651.94 & $1536 \cdot 10$ & 879.03 & $832 \cdot 40$ & 979.50 \\
\hline & 782.53 & $1319 \cdot 30$ & 1511.02 & 1851.08 & $1525 \cdot 04$ & $1552 \cdot 40$ & 846.37 & 1157.50 & $1106 \cdot 71$ \\
\hline & 773.06 & 1183.57 & $1295 \cdot 76$ & $1427 \cdot 22$ & $1122 \cdot 86$ & 1491.93 & $899 \cdot 60$ & $894 \cdot 36$ & $959 \cdot 54$ \\
\hline & $911 \cdot 07$ & 1390.96 & $1531 \cdot 37$ & $1777 \cdot 33$ & $1472 \cdot 77$ & 2004.29 & $835 \cdot 43$ & $1108 \cdot 22$ & $956 \cdot 11$ \\
\hline t. & $292 \cdot 26$ & $948 \cdot 34$ & $587 \cdot 80$ & $726 \cdot 38$ & 930.85 & $917 \cdot 68$ & 262.64 & $289 \cdot 23$ & $365 \cdot 15$ \\
\hline & $381 \cdot 24$ & $803 \cdot 29$ & $827 \cdot 65$ & $972 \cdot 38$ & 857.97 & $1029 \cdot 3$ & $386 \cdot 0$ & 358.00 & $570 \cdot 28$ \\
\hline & $528 \cdot 33$ & $997 \cdot 34$ & $1027 \cdot 46$ & $1048 \cdot 41$ & 897.93 & $1005 \cdot 53$ & $567 \cdot 58$ & $589 \cdot 07$ & \\
\hline
\end{tabular}

Table 6

Hayman's analysis of variance of summer leaf area

$\begin{array}{lrrc}\text { Item } & \text { D.F. } & \text { M.S. } & \text { V.R. } \\ a & 8 & 4,896,630 & 319 \cdot 51^{* * *} \\ b_{1} & 1 & 25,148 & 1 \cdot 64 \mathrm{~N} . \mathrm{S} . \\ b_{2} & 8 & 201,035 & 13 \cdot 12^{* * *} \\ b_{3} & 27 & 59,558 & 3 \cdot 89^{* * *} \\ b & 36 & 90,041 & 5 \cdot 87^{* * *} \\ c & 8 & 47,668 & 3 \cdot 11^{* *} \\ d & 28 & 26,770 & 1 \cdot 75 \mathrm{~N} . \mathrm{S} . \\ \text { Total } & 80 & - & - \\ B & 2 & 73,959 & 4 \cdot 82^{* *} \\ B a & 16 & 20,361 & - \\ B b_{1} & 2 & 6,358 & - \\ B b_{2} & 16 & 17,682 & - \\ B b_{3} & 54 & 11,799 & - \\ B b & 72 & 12,955 & - \\ B c & 16 & 12,104 & - \\ B d & 56 & 17,854 & - \\ B t & 160 & 15,325 & - \\ \text { Total } & 242 & - & - \\ & * \mathrm{P}<0 \cdot 05 ; * * \mathrm{P}<0 \cdot 01 ; * * * \mathrm{P}<0 \cdot 001 .\end{array}$

$(b=1.004 \pm 0.111 ; P=0.001)$, which cuts the $W r$ axis positively, indicating a low level of dominance. The correlation of parental values and $(W r+V r)$ is positive $\left(r=0.939^{* * *}\right)$ indicating directional dominance for small leaf area. This relationship is interesting with regard to the ecology of the populations, and will be considered further below. 


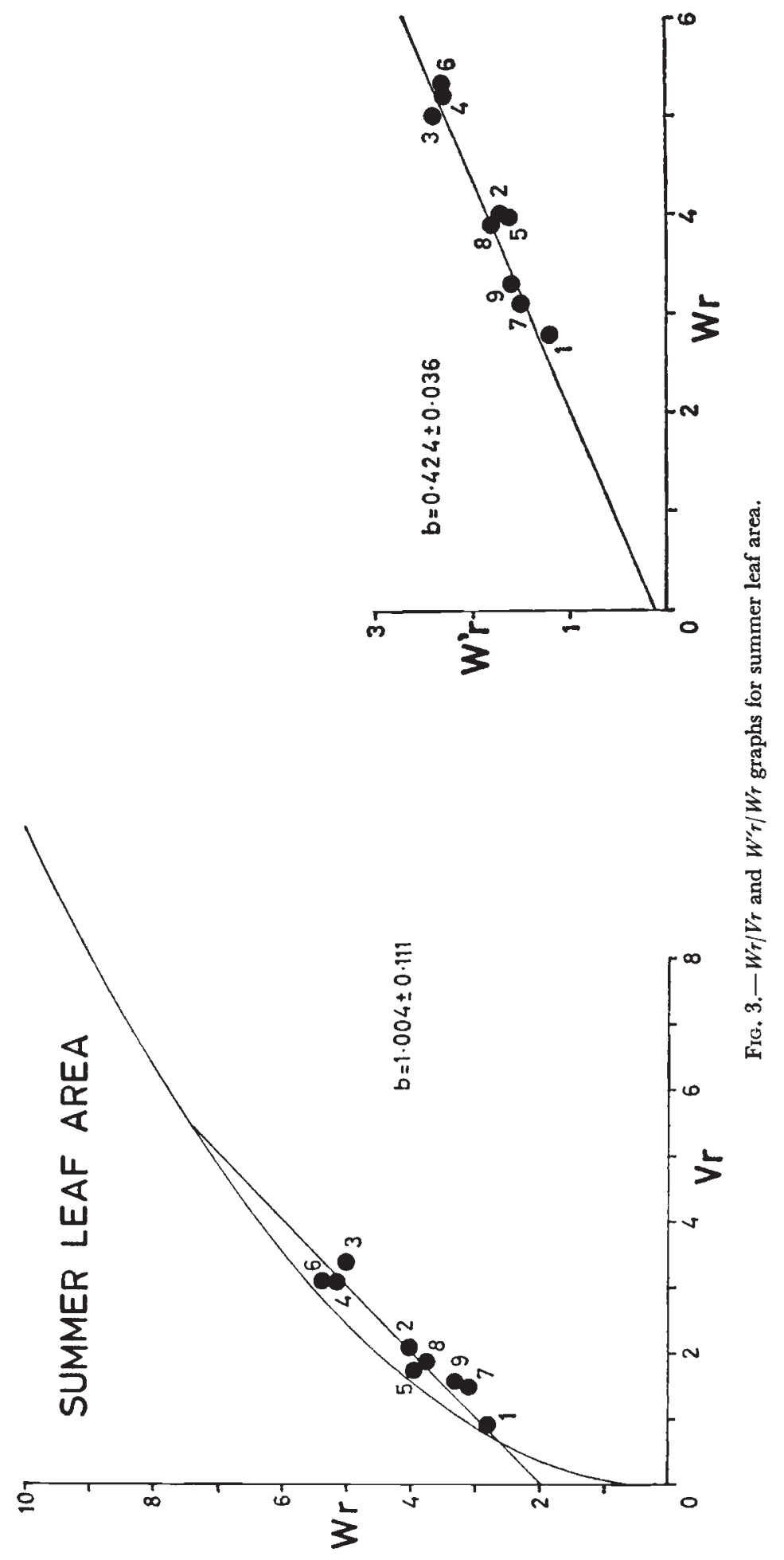


The $W^{\prime} r / W r$ graph (fig. 3 ) shows a similar distritution of parental points, the regression $(b=0.424 \pm 0.036 ; \quad P=0.001)$ not being significantly different from the theoretical +0.50 (Hayman, 1958).

TABLE 7

\begin{tabular}{|c|c|c|c|c|c|c|c|c|c|}
\hline & & & $n$ data $f_{0}$ & eaf $d r y$ & ight as $g_{l}$ & ns/gram J & sh weig & & \\
\hline & $\sigma$ & & & & & & & & \\
\hline q & 1 & 2 & 3 & 4 & 5 & 6 & 7 & 8 & 9 \\
\hline 1. & 0.299 & 0.271 & $0 \cdot 240$ & 0.289 & 0.277 & 0.264 & 0.273 & 0.289 & $0 \cdot 259$ \\
\hline 2. & 0.272 & 0.249 & $0 \cdot 276$ & 0.297 & $0 \cdot 280$ & 0.265 & 0.283 & 0.275 & 0.287 \\
\hline 3. & 0.264 & 0.267 & 0.288 & 0.304 & 0.309 & $0 \cdot 267$ & 0.263 & 0.247 & 0.274 \\
\hline 4. & 0.307 & 0.270 & 0.317 & 0.311 & 0.306 & 0.314 & 0.324 & 0.321 & 0.330 \\
\hline 5. & 0.295 & 0.257 & 0.316 & 0.299 & 0.322 & 0.304 & 0.281 & 0.300 & $0 \cdot 320$ \\
\hline 6. & 0.296 & 0.274 & 0.282 & 0.317 & 0.337 & 0.320 & 0.285 & 0.297 & 0.295 \\
\hline 7. & 0.305 & 0.281 & 0.283 & 0.318 & 0.275 & 0.263 & 0.292 & 0.271 & 0.319 \\
\hline 8. & 0.267 & 0.279 & 0.272 & 0.316 & $0 \cdot 275$ & 0.279 & 0.302 & 0.324 & 0.312 \\
\hline 9. & 0.252 & $0 \cdot 278$ & 0.282 & 0.311 & 0.295 & 0.252 & 0.279 & 0.296 & 0.337 \\
\hline
\end{tabular}

Hayman's analysis of variance for leaf dry weight

$\begin{array}{lrcc}\text { Item } & \text { D.F. } & \text { M.S. } & \text { V.R. } \\ a & 8 & 0.00639 & 12 \cdot 23 * * * \\ b_{1} & 1 & 0.00711 & 8 \cdot 15 \mathrm{~N} . S . \\ b_{2} & 8 & 0.00130 & 1 \cdot 75 \mathrm{~N} . S . \\ b_{3} & 27 & 0.00112 & 2 \cdot 70^{* *} \\ b & 36 & 0.00133 & 2 \cdot 65^{* * *} \\ c & 8 & 0.00154 & 3 \cdot 48 * \\ d & 28 & 0.00037 & 1 \cdot 67 \mathrm{~N} . \mathrm{S} . \\ \text { Total } & 80 & - & - \\ B & 2 & 0.00204 & - \\ B a & 16 & 0.00054 & - \\ B b_{1} & 2 & 0.00087 & - \\ B b_{2} & 16 & 0.00074 & - \\ B b_{3} & 54 & 0.00041 & - \\ B b & 72 & 0.00050 & - \\ B c & 16 & 0.00044 & - \\ B d & 56 & 0.00022 & - \\ & & & - \\ \text { Total } & 242 & - & \\ & * \mathrm{P}<0.05 ; * * \mathrm{P}<0.01 ; * * * \mathrm{P}<0.001 .\end{array}$

(iv) Leaf dry weight

The mean data are presented as grams/gram fresh weight in table 7, and the Hayman's analysis of variance in table 8. Each main effect was tested against its own interaction item as the error variances are hetero- 
GENETIGS OF DIPLOID DAGTYLIS

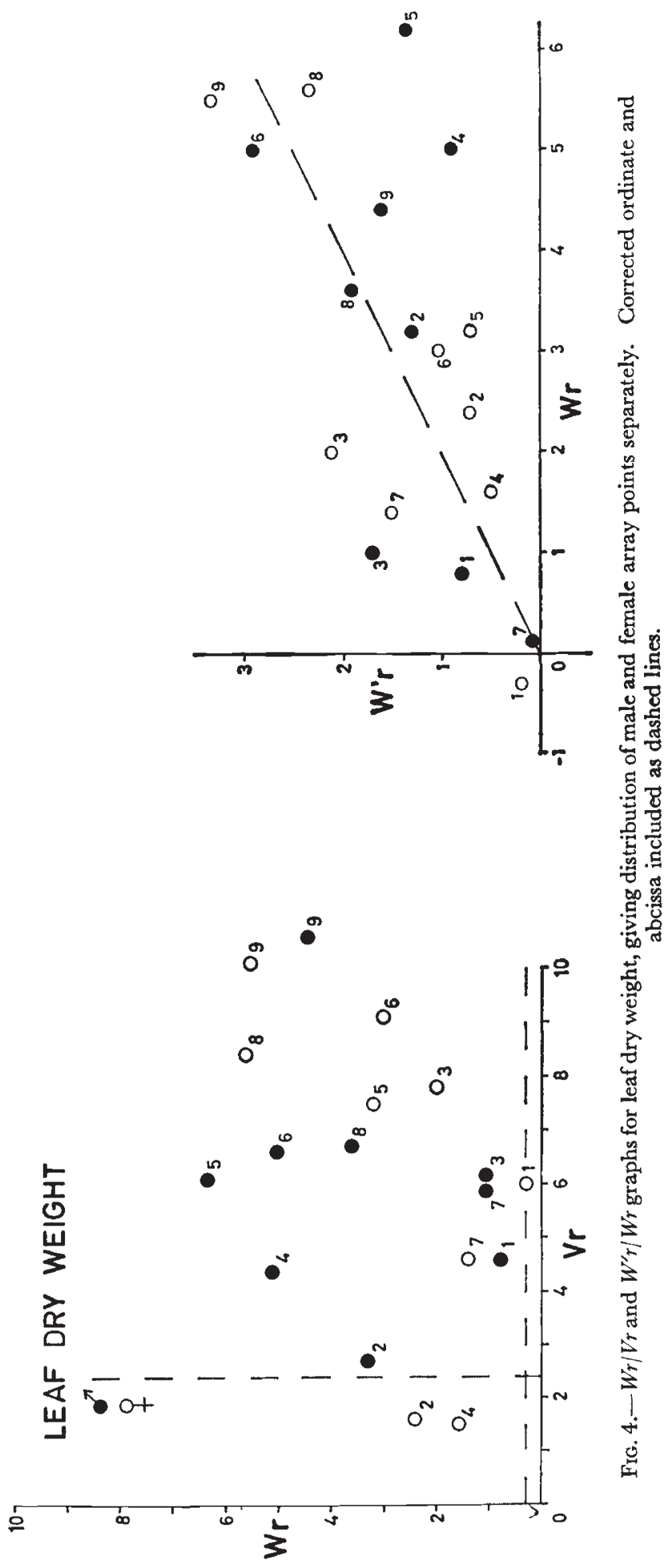


geneous $\left(\chi^{2}{ }_{(5)}=16.69 ; P=0.01\right)$. The analysis of variance indicates the presence of genetic variation between the parental populations (item $a$ ), together with the existence of dominance (item $b$ ). Of the components of $(b)$, only $\left(b_{3}\right)$ is significant, indicating the presence of specific inconsistent dominance interactions, item $(c)$ is also significant, indicating the presence of consistent reciprocal effects.

Analysis by the $W r / V r$ method shows no significant regression (fig. 4). Absence of a significant regression line can be due either to the lack of dominance, in which case the points would be clustered around the position on the limiting parabola $W r=2 V r$, or to some form of non-allelic interaction, when the points are more widely scattered, usually to the right of, and below, the theoretical regression line. The latter case occurs here, however the analysis of variance indicates reasonably large additive genetic differences, and the disturbances could well be caused by reciprocal effects. Reference to the graph shows that six of the nine populations show some measure of increased dominance in the maternal arrays.

The $W^{\prime} r / W r$ regression (fig. 4) is also non-significant, indicating a considerable degree of disturbance, as this graph is not usually disturbed by the presence of non-allelic interaction or heterozygosity (Hayman, 1958; Lawrence, 1964).

\section{(v) Total leaf chlorophyll}

The mean data for total chlorophyll in mg./gm. fresh weight and dry weight respectively are presented in table 9, and the corresponding Hayman's

TABLE 9

Mean data for total chlorophyll as $\mathrm{mg}$./gm. fresh weight (top line) and $\mathrm{mg} . / \mathrm{gm}$. dry weight (bottom line) respectively

\begin{tabular}{|c|c|c|c|c|c|c|c|c|c|}
\hline \multicolumn{10}{|c|}{ ô } \\
\hline 우 & 1 & 2 & 3 & 4 & 5 & 6 & 7 & 8 & 9 \\
\hline \multirow[t]{2}{*}{1.} & $1 \cdot 143$ & $1 \cdot 328$ & $1 \cdot 003$ & $1 \cdot 331$ & $1 \cdot 066$ & $1 \cdot 244$ & $1 \cdot 822$ & $1 \cdot 540$ & $1 \cdot 418$ \\
\hline & $3 \cdot 696$ & $4 \cdot 877$ & $3 \cdot 778$ & $4 \cdot 984$ & $3 \cdot 583$ & $4 \cdot 216$ & $6 \cdot 002$ & $5 \cdot 768$ & $5 \cdot 662$ \\
\hline \multirow[t]{2}{*}{2.} & $1 \cdot 389$ & 1.476 & $0 \cdot 938$ & $1 \cdot 083$ & $1 \cdot 074$ & $1 \cdot 325$ & $1 \cdot 451$ & $1 \cdot 589$ & $1 \cdot 242$ \\
\hline & $5 \cdot 138$ & $5 \cdot 918$ & $3 \cdot 512$ & $4 \cdot 086$ & $4 \cdot 178$ & $4 \cdot 832$ & $5 \cdot 158$ & $5 \cdot 712$ & $4 \cdot 463$ \\
\hline \multirow[t]{2}{*}{3.} & $1 \cdot 131$ & $0 \cdot 742$ & 0.894 & $1 \cdot 088$ & $0 \cdot 861$ & 0.962 & $1 \cdot 214$ & $1 \cdot 219$ & $1 \cdot 127$ \\
\hline & $4 \cdot 520$ & $2 \cdot 695$ & $3 \cdot 081$ & $3 \cdot 427$ & $2 \cdot 724$ & 3.417 & $4 \cdot 621$ & $4 \cdot 484$ & $3 \cdot 999$ \\
\hline \multirow[t]{2}{*}{4.} & $1 \cdot 256$ & 0.922 & $0 \cdot 806$ & $1 \cdot 732$ & $1 \cdot 024$ & 0.930 & $1 \cdot 563$ & $1 \cdot 401$ & $1 \cdot 181$ \\
\hline & $4 \cdot 666$ & $3 \cdot 095$ & $2 \cdot 587$ & $5 \cdot 646$ & $3 \cdot 436$ & $2 \cdot 934$ & $4 \cdot 826$ & $4 \cdot 434$ & $3 \cdot 583$ \\
\hline \multirow[t]{2}{*}{5.} & 0.929 & 0.876 & $0 \cdot 646$ & 0.834 & 1.074 & $0 \cdot 817$ & $1 \cdot 137$ & 0.976 & $1 \cdot 186$ \\
\hline & $3 \cdot 376$ & $3 \cdot 129$ & $2 \cdot 129$ & $2 \cdot 732$ & $3 \cdot 345$ & $2 \cdot 431$ & $4 \cdot 027$ & $3 \cdot 546$ & $3 \cdot 707$ \\
\hline \multirow[t]{2}{*}{6.} & $1 \cdot 233$ & $1 \cdot 256$ & $0 \cdot 834$ & $1 \cdot 169$ & $1 \cdot 017$ & $1 \cdot 040$ & $1 \cdot 166$ & $1 \cdot 137$ & $1 \cdot 307$ \\
\hline & $4 \cdot 664$ & $4 \cdot 765$ & $3 \cdot 123$ & $3 \cdot 793$ & $3 \cdot 338$ & $3 \cdot 260$ & $4 \cdot 095$ & $4 \cdot 077$ & $4 \cdot 421$ \\
\hline \multirow[t]{2}{*}{7.} & 1.563 & $1 \cdot 454$ & $1 \cdot 265$ & $1 \cdot 555$ & $1 \cdot 139$ & $1 \cdot 316$ & $1 \cdot 814$ & 1.482 & $1 \cdot 454$ \\
\hline & $5 \cdot 725$ & $5 \cdot 168$ & $4 \cdot 466$ & $4 \cdot 890$ & $4 \cdot 154$ & $5 \cdot 001$ & $5 \cdot 926$ & $4 \cdot 906$ & $5 \cdot 205$ \\
\hline \multirow[t]{2}{*}{8.} & $1 \cdot 682$ & 1.465 & $1 \cdot 172$ & $1 \cdot 449$ & $1 \cdot 323$ & $1 \cdot 168$ & $1 \cdot 733$ & $1 \cdot 689$ & $1 \cdot 331$ \\
\hline & $5 \cdot 840$ & $5 \cdot 334$ & $4 \cdot 691$ & $4 \cdot 519$ & $4 \cdot 421$ & 3.940 & $7 \cdot 281$ & $5 \cdot 214$ & 4.507 \\
\hline \multirow[t]{2}{*}{9.} & 1.452 & 1.445 & $1 \cdot 092$ & $1 \cdot 135$ & $1 \cdot 100$ & $1 \cdot 201$ & 1.810 & $1 \cdot 280$ & 1.431 \\
\hline & $5 \cdot 637$ & $5 \cdot 062$ & 3.983 & 3.652 & $3 \cdot 726$ & $4 \cdot 772$ & $5 \cdot 701$ & $4 \cdot 542$ & $4 \cdot 237$ \\
\hline
\end{tabular}


analysis of variance in table 10. Each main effect in the analysis of variance was tested against its own error variance, these being heterogeneous (mg./gm. F.W.; $\chi^{2}{ }_{(5)}=27 \cdot 1 ; \quad \mathrm{P}=0 \cdot 001$ : mg./gm. D.W.; $\chi^{2}{ }_{(5)}=9 \cdot 7 ;$ $\mathrm{P}=0 \cdot 1-0 \cdot 05)$.

\section{TABLE 10}

Hayman's analysis of variance for total chlorophyll as mg./gm. F.W. and mg./gm. D.W. Wearden's test is included, as both (c) and (d) are significant

\begin{tabular}{|c|c|c|c|c|c|c|c|}
\hline \multirow[b]{2}{*}{ Item } & \multicolumn{4}{|c|}{ Fresh wt. } & \multicolumn{3}{|c|}{ Dry wt. } \\
\hline & D.F. & M.S. & & earden's test & M.S. & & earden's test \\
\hline$a$ & 8 & $1.538 * * *$ & $\frac{a}{c}$ & $21 \cdot 07 * * *$ & $20 \cdot 450 * * *$ & $\frac{a}{c}$ & $17 \cdot 74 * * *$ \\
\hline$b_{1}$ & 1 & 0.496 N.S. & $\frac{b_{1}}{d}$ & $17 \cdot 10 * * *$ & 0.747 N.S & $\frac{b_{1}}{d}$ & -N.S. \\
\hline$b_{2}$ & 8 & $0 \cdot 163^{* *}$ & $\frac{b_{2}}{d}$ & $5 \cdot 62 * * *$ & $3.728 * * *$ & $\frac{b_{2}}{d}$ & $7 \cdot 67 * * *$ \\
\hline$b_{3}$ & 27 & $0 \cdot 057 * * *$ & $\frac{b_{3}}{d}$ & -N.S. & $0.784 * *$ & $\frac{b_{3}}{d}$ & -N.S. \\
\hline$b$ & 36 & $0 \cdot 093 * * *$ & $\frac{b}{d}$ & $3 \cdot 21 * *$ & $1 \cdot 437 * * *$ & $\frac{b}{d}$ & $2 \cdot 96 * *$ \\
\hline$c$ & 8 & $0.073 * * *$ & $\frac{c}{d}$ & $2 \cdot 62 *$ & $1 \cdot 153^{* *}$ & $\frac{c}{d}$ & $2 \cdot 37 *$ \\
\hline$d$ & 28 & $0 \cdot 029 * *$ & & - & $0 \cdot 486 * *$ & & - \\
\hline Total & 80 & - & & - & - & & - \\
\hline$B$ & 2 & $0 \cdot 228$ & & - & 1.927 & & - \\
\hline$B a$ & 16 & $0 \cdot 024$ & & - & 0.245 & & - \\
\hline$B b_{1}$ & 2 & $0 \cdot 266$ & & - & 1.636 & & - \\
\hline$B b_{2}$ & 16 & 0.049 & & - & 0.590 & & - \\
\hline $\mathrm{Bb}_{3}$ & 54 & 0.021 & & - & 0.330 & & - \\
\hline$B b$ & 72 & 0.034 & & - & 0.424 & & - \\
\hline$B c$ & 16 & $0 \cdot 010$ & & - & 0.273 & & - \\
\hline$B d$ & 56 & 0.013 & & - & $0 \cdot 231$ & & - \\
\hline Total & 242 & - & & - & - & & - \\
\hline
\end{tabular}

From the analysis of variance there is good evidence of genetic variation between the populations in both characters (item $a$ ), together with the existence of some dominance (item $b$ ). Of the component of dominance, only $\left(b_{2}\right)$ and $\left(b_{3}\right)$ are significant, indicating the presence of gene asymmetry, and specific inconsistent reciprocal differences. Both items $(c)$ and $(d)$ are significant, pointing to the presence of consistent and inconsistent reciprocal effects. Wearden's (1964) test shows that item $(c)$ is in fact significantly greater than $(d)$, indicating that these reciprocal effects are of considerable magnitude in both characters. There are also differences in the significance of the components of $(b)$ when tested against $(d)$. In the chlorophyll mg./gm. fresh weight analysis both items $\left(b_{1}\right)$ and $\left(b_{2}\right)$ are significant, suggesting that some directional dominance is present, along with gene asymmetry. In 
the dry weight analysis only gene asymmetry $\left(b_{2}\right)$ is a significant component of $(b)$.

Investigation of the genetical situation by the $W r / V r$ graph (fig. 5) shows that there is a significant joint regression in the chlorophyll $\mathrm{mg}$. $/ \mathrm{gm}$. fresh weight graph $(b=0.797 \pm 0.130 ; \mathbf{P}=0.001)$, but not in the chlorophyll mg./gm. dry weight graph (figs. 5-6). However, there is a significant male regression $(b=0.623 \pm 0.193 ; P=0.05-0.01)$. Obviously there is greater interaction occurring on the female side, although it is not consistently in one direction (fig. 5).

In neither case is there any correlation of the parental values with $(W r+V r)$. The correction of ordinate and abcissa for the environmental component $\left(E_{2}\right)$ in the dry weight graph, reduces the level of dominance to approximately that of the fresh weight graph.

In the $W^{\prime} r / W r$ analysis there is again a significant regression in the fresh weight graph $(b=0.328 \pm 0.076 ; P=0.001)$ and a similar order of parental points (fig. 5). There is no regression in the dry weight graph in either sex (fig. 6).

\section{Discussion}

Previous studies upon the characters considered here, using similar methods, are considerably biased in favour of flowering time. There appears to be no general pattern of dominance relations prevailing between or even within populations or species, genetic control ranging from dominance for earliness as in Triticum cultivars (Crumpacker and Allard, 1962) through ambidirectional dominance as in wild Melandrium (Lawrence, 1963, 1964) and Secale species hybrids (Sun, 1962), to dominance for late flowering as in Pisum cultivars (Rowlands, 1964).

The present study shows the presence of a large additive component, with a degree of dominance for earliness, this is not correlated with geographical distribution, as in leaf area, but does indicate that in these subspecies populations of Dactylis there is directional selection for early flowering.

Both the leaf areas studied have a considerable additive component, but differ in the degree and type of dominance expressed, also the degree of genetic interaction apparent in the $W r / V r$ graphs. Flag leaf area shows ambidirectional dominance, suggesting a history of stabilising selection (Mather, 1960), and the parental points on the $W r / V r$ graph tend to form a slight curve, concave upwards, suggesting that some form of complementary gene action may be present (Mather, 1967). Summer leaf area on the other hand shows directional dominance for small size, suggesting a history of directional selection. It is reasonable to suggest that this is a direct response to the climatic conditions experienced by the original subspecies populations sampled, those adapted to a climate of summer drought having the smallest summer leaves. This directional selection pressure operating on a geographical basis is the reverse of that found previously for winter growth in the same material (Parker, 1968), and by Cooper (1964) in Lolium and Dactylis.

Leaf dry weight has not been previously investigated, although some data on whole plant, and fruit dry weight in Lycopersicum crosses has been published by Kheiralla and Whittington (1962). In neither of these characters was there the large amount of genetic disturbance present as in Dactylis. This appears to be caused by large consistent reciprocal differences tending to 


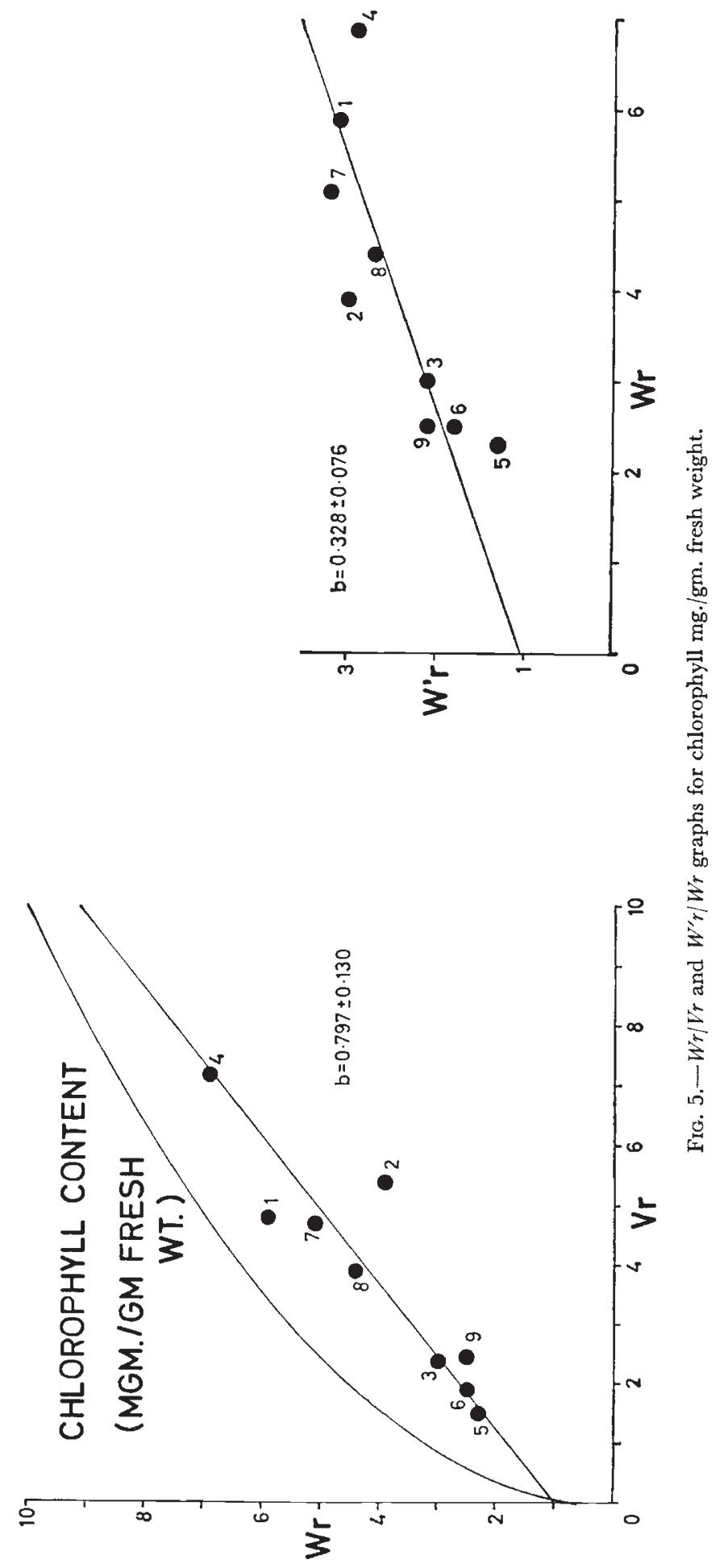




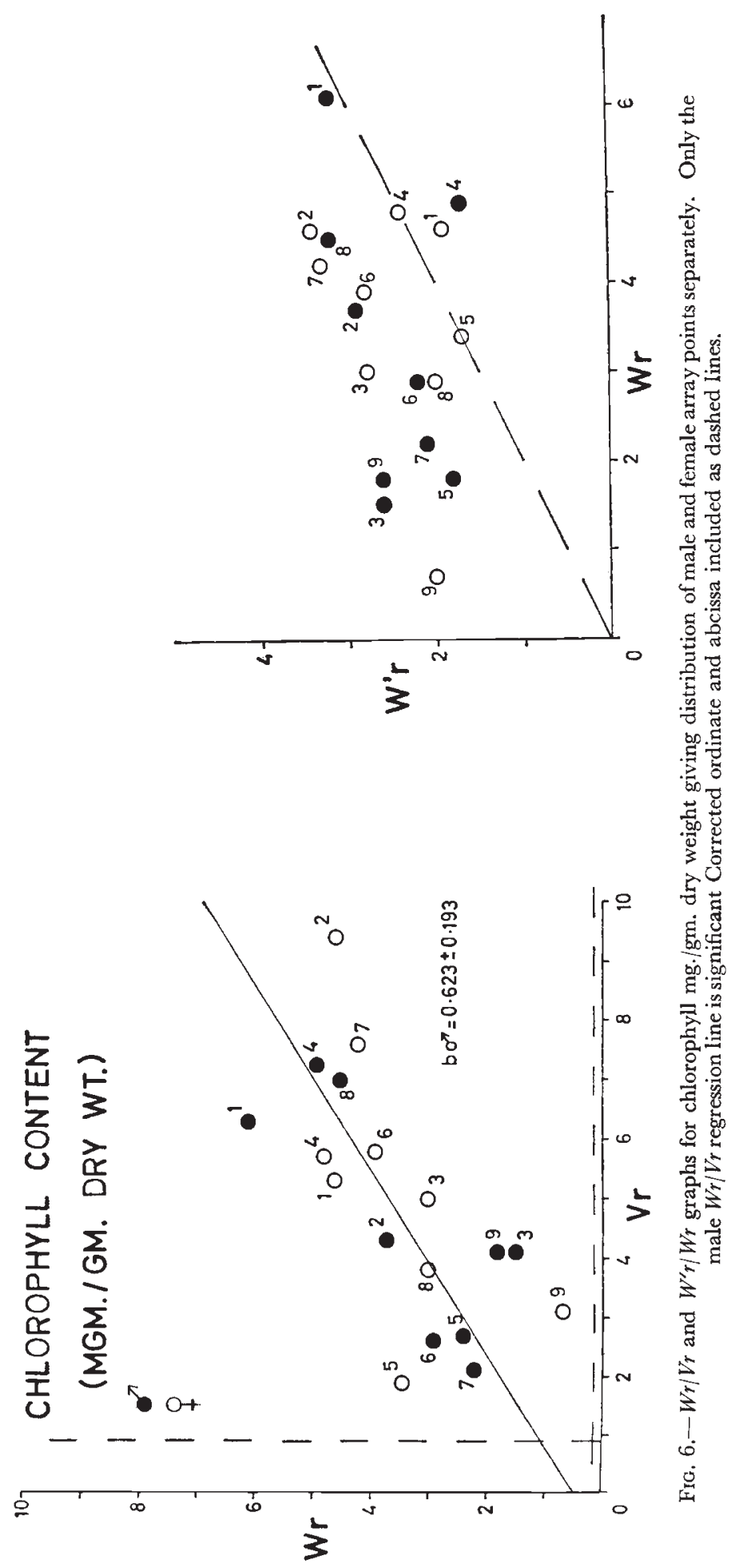


increase the level of dominance in progeny of the maternal parents. There are also specific dominance interactions occurring in all progeny but those of subspecies juncinella (2) and aschersoniana (4).

Analyses of cholorophyll content once more indicated that a large additive component was present with a degree of ambidirectional dominance for the joint analysis of chlorophyll content on a fresh weight basis, but interaction again caused mainly by factors detected by the $(c)$ item in the Hayman's analysis, in the chlorophyll data calculated on a dry weight basis. That this effect was mainly maternal was shown by the considerable disturbance of the famale $W r / V r$ graph compared to the male $W r / V r$. Hanover (1966), in his study of terpene production in Pinus, also showed that both additive and epistatic effects were present in hybrids, although his method of analysis is not comparable to the present one. Lamprecht and Stevens (1964), on the other hand, in their analysis of nitrogen content in Lucerne showed a very large $(c)$ component, which did not affect the $W r / V r$ graph at all; there was, however, no significant $(d)$ component to add its complicating effects.

The one characteristic feature occurring in all the analyses considered is the persistent occurrence of consistent and inconsistent reciprocal differences either singly or together. It is doubtful if these effects are entirely due to variation in seed weight, the effect of which usually decreases quite rapidly with time (Thomas, 1966), although this cannot be completely ruled out. The alternative, the presence of nuclear-cytoplasmic interactions, appears more probable at the adult plant stage (Hayward, 1967; Lawrence, 1964).

\section{SUMMARY}

1. The genetic analysis of several adult plant characters in diploid Dactylis was undertaken.

2. The pattern of variation between the subspecies samples was mainly additive in nature, with a considerable level of consistent reciprocal differences, not always entirely maternal, and gene-cytoplasm interactions.

3. The results are discussed briefly in relation to the distribution of the populations.

Acknowledgments.- This work was carried out during the tenure of a Ministry of Agriculture scholarship at the Welsh Plant Breeding Station, and submitted in partial fulfilment of a Ph.D. thesis. I wish to thank Professor P. T. Thomas for his general guidance, and Professor J. L. Jinks for his subsequent comments on, and discussion of, the work.

\section{REFERENGES}

ARnon, D. I. 1949. Copper enzymes in isolated chloroplasts. Polyphenol oxidase in Beta vulgaris. Plant Physiol., 24, 1 .

COOPER, J. P. 1964. Climatic variation in forage grasses I. J. Appl. Ecol., 1, 45-61.

GRUMPACKER, D. W., AND ALLARD, R. W. 1962. A diallel cross analysis of heading date in wheat. Hilgardia, 32, 275-318.

Dickinson, A. G., AND Jinks, J. L. 1956. A generalised analysis of diallel crosses. Genetics, 41, 65-78.

hanover, J. w. 1966. Genetics of Terpenes. I. Gene control of monoterpene levels in Pinus monticola Dougl. Heredity, 21, 73-84.

HAYMAN, B. I. 1954. Analysis of variance of diallel tables. Biometrics, 10, 235-244.

hayman, в. I. 1958. The theory and analysis of diallel cross II. Genetics, 43, 63-85.

$2 \mathrm{C}$ 
HAYWARD, M. D. 1967. The genetic organisation of natural populations of Lolium perenne. II. Inflorescence production. Heredity, 22, 105-116.

JINKs, J. L. 1954. The analysis of continuous variation in a diallel cross of Nicotiana rustica varieties. Genetics, 39, 767-788.

KEMP, C. D. 1960. Methods of estimating the leaf area of grasses by linear measurements. Ann. Bot., N.S., 24, 491-499.

Kheiralla, A. I., AND Whittington, w. J. 1962. Genetic analysis of growth in tomato: the $\mathrm{F}_{1}$ generation. Ann. Bot., N.S., 26, 489-504.

LAMPRECHT, M. P., AND STEVENS, J. M. 1964. A genetic study of certain characteristics of the Lucerne cultivar "South African Standard" (Medicago sativa L.). S. Afr. Tydskrif. Landbouwet., 7, 749-762.

LAWRENCE, c. w. 1963. Genetic studies on wild populations of Melandrium II. Heredity, $18,149-163$.

LAWRENCE, c. W. 1964. Genetic studies on wild populations of Melandrium III. Heredity, 19, 1-19.

mackinnay, G. 1941. Absorption of light by chlorophyll solutions. F. Biol. Chem., 140, 315-322.

MATHER, K. 1967. Complementary and duplicate gene interactions in biometrical genetics. Heredity, 22, 97-103.

PARKer, P. F. 1968. Genetic variation in diploid Dactylis. Heredity, 23, 279-300.

Rowlands, D. G. 1964. Genetic control of flowering in Pisum sativum L. Genetica, 35, 75-94.

sun, s. 1962. Cytogenetic studies in Secale. Ph.D. Thesis, University of Wales (Aberystwyth).

Thомas, R. L. 1966. The influence of seed weight on seedling vigour in Lolium perenne $\mathbf{L}$. Ann. Bot., 30, 111-121.

WEARDEN, s. 1964. Alternative analyses of the diallel cross. Heredity, 19, 669-680. 